\title{
DESEMPENHO DE FRANGOS DE CORTE ALIMENTADOS COM RAÇÃO CONTENDO FARELO DE ARROZ E ENZIMAS ${ }^{1}$
}

\begin{abstract}
RESUMO - O presente trabalho foi realizado com o objetivo de avaliar a viabilidade da utilização de xilanase e farelo de arroz em rações suplementadas com fitase para frangos de corte na fase de um a 21 dias de idade. No experimento foram utilizados 540 pintos machos de um dia da marca Ross, distribuídos em um delineamento inteiramente casualizado, em arranjo fatorial 4 x $2+1$ (xilanase x farelo de arroz + testemunha), com quatro repetições de 15 aves por parcela. A ração testemunha à base de milho e de farelo de soja sem suplementação com enzimas foi formulada para atender às exigências nutricionais das aves. As rações com inclusão de farelo de arroz, também à base de milho e farelo de soja, foram suplementadas com 900 unidades de fitase $/ \mathrm{kg}$. Todas a rações foram balanceadas segundo Rostagno et al. (2000), exceto para o fósforo disponível e cálcio nas rações contendo farelo de arroz, cujos níveis foram reduzidos $(0,22 \%$ e $0,75 \%)$. O farelo de arroz foi incluído em $10 \%$ ou $20 \%$ na ração suplementada com quatro níveis de xilanase $(0,200,400$ ou 600 unidades $/ \mathrm{kg}$ ). A utilização da xilanase não afetou o consumo de ração. As aves que receberam ração com $20 \%$ de farelo de arroz apresentaram consumo $2,6 \%$ menor e conversão alimentar 2,2\% melhor do que as
\end{abstract}

\author{
NEUDI ARTEMIO SCHOULTEN ${ }^{2}$ \\ ANTÔNIO SOARES TEIXEIRA ${ }^{3}$ \\ PAULO BORGES RODRIGUES ${ }^{3}$ \\ RILKE TADEU FONSECA DE FREITAS ${ }^{3}$ \\ ADEMIR JOSÉ CONTE ${ }^{4}$ \\ HUNALDO OLIVEIRA SILVA ${ }^{5}$
}

aves que receberam ração com $10 \%$ de farelo de arroz na fase de 1 a 21 dias. Em comparação com a testemunha, o consumo para a ração com $20 \%$ de farelo de arroz foi menor com menos de 600 unidades $/ \mathrm{kg}$ de xilanase, e o ganho de peso foi menor sem xilanase e com $20 \%$ de farelo de arroz com até 200 unidades $/ \mathrm{kg}$ de xilanase na fase de 1 a 21 dias. O melhor ganho de peso foi estimado para 391 unidades $/ \mathrm{kg}$ de xilanase para a ração para $10 \%$ de farelo de arroz na fase de 1 a 21 dias; para a ração com $20 \%$ de farelo de arroz, o nível ótimo de xilanase está acima dos níveis utilizados neste experimento. Os melhores resultados de conversão alimentar foram estimados para 350 e 425 unidades $/ \mathrm{kg}$ de xilanase de 1 a 21 dias, respectivamente, para 10 e $20 \%$ de farelo de arroz. Dessa forma, pode-se concluir que a elevação do nível de farelo de arroz na ração eleva a quantidade de xilanase necessária para reduzir os efeitos antinutritivos. Sem xilanase, a utilização de farelo de arroz na ração não deve ultrapassar 12\%. Com 400 unidades de xilanase por kg de ração, a utilização de até $20 \%$ de farelo de arroz propicia desempenho semelhante ao da raçãotestemunha, sem farelo de arroz e sem xilanase. A maximização de desempenho das aves com ração contendo acima de $20 \%$ de farelo de arroz necessita de suplementação de xilanase acima de 600 unidades $/ \mathrm{kg}$.

TERMOS PARA INDEXAÇÃO: Enzima, farelo de arroz, fitase, frangos de corte, xilanase.

\section{PERFORMANCE OF BROILER CHICKENS FED WITH DIET CONTAINING RICE BRAN AND ENZYMES}

\author{
ABSTRACT - The present work was conducted to \\ supplemented with phytase for broiler chickens. In the \\ evaluate the use of xylanase and rice bran in rations \\ experiment were utilized 540 one day old male Ross

\footnotetext{
1. Parte da tese de doutorado apresentada à UNIVERSIDADE FEDERAL DE LAVRAS/UFLA, Caixa Postal 37 37200-000 - Lavras, MG, pelo primeiro autor

2. Professor da Escola Agrotécnica Federal de Rio do Sul -SC.

3. Professor da UFLA/Departamento de Zootecnia.

4. Professor da Escola Agrotécnica Federal de Cuiabá - MT.

5. Estudante de doutorado DZO/UFLA.
} 
chicks, allocated into a completely randomized design in a $4 \times 2+1$ factorial arrangement (xylanase $\mathrm{x}$ rice bran + control) with four replicates of 15 birds per pen. The control ration was based on corn and soybean meal without enzyme supplementation were formulated to reach the chickens nutrient requirements. The rations with the addition of rice bran also were based on corn and soybean meal were supplemented with 900 units of phytase $/ \mathrm{kg}$. All the rations were formulated according to Rostagno et al. (2000), except for available phosphorus and calcium in the rations containing rice bran, in which the levels were reduced $(0.22 \%$ and $0.75 \%)$. Rice bran was added in $10 \%$ or $20 \%$ in the ration supplemented with four levels of xylanase $(0$, 200,400 or 600 units $/ \mathrm{kg}$ ). The use of xylanase did not affect feed intake as well as any treatments tested. The chickens fed ration with $20 \%$ of rice bran shown feed intake $2.6 \%$ lower and feed conversion $2.2 \%$ better than the chickens fed ration with $10 \%$ of rice bran from 1 to 21 days. As compared with the control ration, feed intake for ration with $20 \%$ of rice bran shown lower for ration supplemented with less than 600 units $/ \mathrm{kg}$ of xylanase and weight gain was lower without xylanase and with $20 \%$ of rice bran up to 200 units $/ \mathrm{kg}$ of xylanase from 1 to 21 days. The best weight gain was estimated for 391 units $/ \mathrm{kg}$ of xylanase for the ration supplemented with $10 \%$ of rice bran from 1 to 21 days and for the ration with $20 \%$ of rice bran, the optimum level of xylanase should be higher than the levels utilized in this experiment for both phases. The best results of feed conversion were estimated as 350 and 425 units $/ \mathrm{kg}$ of xylanase from 1 to 21 days, respectively, by using rations with addition of 10 and $20 \%$ of rice bran. Accord to the data the increase of the level of rice bran in the ration also the xylanase should be supplemented in order to reduce the detrimental effects on chickens performance. Rations without xylanase, the addition of rice bran should not exceed $12 \%$. Therefore supplementation of 400 units of xylanase per $\mathrm{kg}$ of ration, allow to add up to $20 \%$ of rice bran in the ration. The maximization of chickens performance fed ration with higher than $20 \%$ of rice bran should be supplementation of xylanase higher than 600 units/kg of ration.

INDEX TERMS: Broiler chickens, enzymes, phytase, rice bran, xylanase.

\section{INTRODUÇÃO}

Um dos componentes que mais oneram o custo de produção de frangos de corte nos sistemas de criação intensiva é a ração, representando cerca de $70 \%$ desse custo. As fontes de energia e proteína são os ingredientes mais onerosos, seguidos pela de fósforo, que é o ingrediente de origem mineral mais caro, participando com 2 a 3\% do custo total da ração. Assim, a busca por alimentos alternativos para substituir o milho e o farelo de soja, visando a reduzir os custos de produção, tem sido uma preocupação generalizada no sistema de produção e pesquisa avícola no Brasil e no mundo.

Um alimento alternativo de grande destaque para a alimentação de animais é o farelo de arroz, produzido em grandes quantidades no país. Por outro lado, na maioria das vezes, essas fontes alternativas apresentam fatores antinutricionais que limitam ou impedem a sua utilização. Atualmente, alguns desses fatores antinutricionais podem ser contornados pela adição de enzimas exógenas à ração.

O farelo de arroz constitui uma boa fonte de energia na alimentação das aves, em substituição ao milho, devido à sua composição nutritiva, pois contém altos níveis de lipídeos, proteína e fósforo. Entretanto, a sua utilização é limitada devido à presença de altas porcentagens de ácido fítico e fibra, que prejudicam a digestibilidade de todos os componentes nutritivos da dieta.

Polissacarídeos que fazem parte principalmente da parede celular, denominados polissacarídeos nãoamídicos, não são ou são pouco digeridos pelas aves, pois essas não possuem as enzimas apropriadas para a sua hidrólise. Com isso, há uma redução na quantidade de energia disponível para o animal e um aumento da viscosidade da digesta, o que prejudica a digestibilidade dos nutrientes como um todo. Segundo Shibuta et al. (1985), a fibra do farelo de arroz é composta por $38 \%$ de hemicelulose, $28 \%$ de celulose, $27 \%$ de lignina e $7 \%$ de pectina. A arabinose e xilose, que ligam-se para formar os arabinoxilanos, compõem $80 \%$ da hemicelulose.

As pesquisas com enzimas têm demonstrado a importância dessas substâncias para reduzir o efeito negativo dos fatores antinutricionais e melhorar a eficiência alimentar. A fitase apresenta capacidade efetiva de melhorar o aproveitamento do fósforo fítico, principalmente de alimentos que apresentam alto teor de fitato e, dessa forma, reduz o potencial poluidor das excretas, tornando a atividade avícola ecologicamente mais correta. 
As enzimas digestivas carboidrases têm sido usadas para hidrolisar os polissacarídeos não-amídicos, aumentando a disponibilidade da energia dos alimentos. Além disso, atuam reduzindo a viscosidade da digesta, conseqüentemente aumentando a digestibilidade de todos os componentes nutritivos dos alimentos. Algumas indústrias produzem essas enzimas comercialmente, as quais devem e necessitam ser testadas por meio de pesquisas científicas para a avaliação de sua eficácia, principalmente as carboidrases, que são preparadas e mais utilizadas na Europa, onde os ingredientes a que se destinam são os polissacarídeos não-amídicos provenientes de cereais brancos como o trigo, cevada e centeio.

Comprovada a eficácia das carboidrases, essas poderiam promover o aumento da utilização de subprodutos de origem vegetal, reduzindo os custos de produção das rações, além de colaborar com a proteção ambiental devido à redução da excreção de nutrientes nas excretas.

O farelo de arroz é o subproduto do polimento ou beneficiamento do arroz após a remoção da casca silícica e lignocelulósica, constituído da camada intermediária entre a casca e o endosperma. É constituído de pericarpo, testa, aleurona e gérmen, além de quantidade variável de amido, dependendo do grau de polimento. A operação de beneficiamento do arroz com casca para obtenção do arroz branco produz em média $8 \%$ de farelo de arroz, podendo variar, segundo relatos de Domene (1996), de 4 a 12\% do peso do grão.

$\mathrm{Na}$ safra 99/00, o Brasil produziu 11.533.800 toneladas de arroz em casca (AGRIANUAL..., 2001). Considerando o rendimento médio de farelo de arroz resultante do processo de beneficiamento, pode-se estimar uma disponibilidade anual no Brasil de cerca de 920 mil toneladas. Os preços desse subproduto são normalmente muito inferiores aos preços do milho; portanto, esse poderia constituir uma boa fonte alternativa de alimento para redução dos custos de produção de frangos.

O farelo de arroz apresenta características importantes, principalmente na sua composição química, como o alto teor de óleo, que possibilita sua utilização como fonte de energia para as aves, em substituição ao milho. Ali et al. (1998), ao analisarem o farelo de arroz de diferentes variedades, encontraram óleo variando de 16,72 a $21,40 \%$. O nível de proteína bruta do farelo de arroz é superior ao do milho. Na literatura encontramse valores de proteína bruta variando de 8 a $17 \%$. Ali et al. (1998), ao analisarem o farelo de arroz de diferentes variedades, encontraram proteína bruta de 14,37 a $16,25 \%$. Com relação à composição mineral, é rico em fósforo e manganês, além de níveis de cobre, ferro e zinco superiores aos do milho.

A composição de todos os nutrientes, mas principalmente dos minerais, varia enormemente de acordo com o método de polimento do arroz integral no processamento, o que segundo Ravindran e Blair (1991), deve-se principalmente ao nível de contaminação com casca de arroz, o qual, por sua vez, depende do equipamento utilizado para o beneficiamento.

\section{MATERIAL E MÉTODOS}

O experimento foi conduzido na Unidade Experimental do Setor de Avicultura da Escola Agrotécnica Federal de Cuiabá (EAFC-MT), no período de 25 de janeiro a 8 de março de 2001. Foram utilizados 540 pintos machos de um dia, da marca comercial Ross, alojados em um galpão de alvenaria, dividido internamente em 36 boxes de $4 \mathrm{~m}^{2}$ cada um. O manejo foi realizado seguindo orientações do manual de manejo de frangos da Agroceres Ross (2001). A água e ração foram fornecidas à vontade. A avaliação de desempenho foi feita aos 21 dias, pesando-se as aves de cada parcela, e o consumo de ração foi determinado pela pesagem da ração fornecida no início menos a sobra no comedouro ao final do período.

A ração à base de milho, farelo de soja e farelo de arroz foi formulada para ser isonutritiva, sem considerar os efeitos da enzima, visando a atender todas as exigências nutricionais, segundo Rostagno et al. (2000), com exceção do fósforo e cálcio nas rações experimentais contendo farelo de arroz, que foi de $0,22 \mathrm{e}$ $0,75 \%$, respectivamente. O fósforo disponível foi calculado sem considerar o efeito da fitase. Foi formulada uma ração à base de milho e de farelo de soja sem utilização de enzimas, semelhante à ração utilizada na criação comercial de frangos, que serviu como testemunha para comparação dos resultados dos tratamentos em que foram utilizados as enzimas e o farelo de arroz. A ração basal, exceto a testemunha, foi suplementada com fitase, na dosagem de 900 FTU/kg e xilanase com diferentes níveis, dependendo do tratamento, além de minerais e vitaminas. A xilanase utilizada tem atividade enzimática endo-1-4- $\beta$-xilanase e a utilização de $1 \mathrm{~g}$ de xilanase por tonelada de ração corresponde a 1 unidade de xilanase/kg de ração. Na Tabela 1 estão as fórmulas e a composição nutritiva das rações utilizadas no experimento. 
Os experimentos foram conduzidos em um delineamento experimental inteiramente casualizado, em um esquema fatorial 4 × $2+1(0,200,400$ e $600 \mathrm{~g}$ de xilanase/tonelada e 10 ou $20 \%$ de farelo de arroz, mais um tratamento testemunha sem enzimas e sem farelo de arroz), totalizando 9 tratamentos com 15 aves por parcela experimental, quatro repetições por tratamento, num total de 36 parcelas experimentais. As análises estatísticas dos resultados obtidos foram realizadas utilizando o programa ESTAT 2.0 (Sistema para Análises estatísticas) desenvolvido pelo pólo computacional do Departamento de Ciências Exatas da UNESP - Jaboticabal, (UNESP, 1992). As estimativas dos níveis de in- clusão de xilanase foram obtidas mediante o uso dos modelos de regressão linear ou quadrática, conforme o ajustamento dos dados obtidos para cada variável, interpretando-se as respostas biológicas das aves. As comparações entre as médias das variáveis estudadas das aves que receberam a ração-testemunha e as médias para cada um dos tratamentos das aves que receberam a ração com farelo de arroz e enzimas foram feitas mediante o teste de comparação de médias de Dunnett, com $\mathrm{P}<0,05$.

As análises das amostras dos alimentos e das rações foram realizadas no Laboratório de Pesquisa Animal do DZO-UFLA, segundo metodologia da AOAC (1990).

TABELA 1 - Formulação e composição nutritiva das rações experimentais para os frangos na fase de 1 a 21 dias de idade.

\begin{tabular}{lccc}
\hline \multicolumn{1}{c}{ Ingrediente (\%) } & Testemunha & $\mathbf{1 0 \%}$ FA & $\mathbf{2 0 \%}^{\mathbf{F}} \mathbf{A}^{\mathbf{2}}$ \\
\hline Milho moído & 61,48 & 52,74 & 42,26 \\
Farelo de soja & 33,69 & 32,43 & 31,51 \\
Farelo de arroz & 0,00 & 10,00 & 20,00 \\
Óleo de soja & 0,73 & 1,61 & 3,08 \\
Fosfato bicálcio & 1,74 & 0,46 & 0,34 \\
Calcário calcítico & 0,96 & 1,32 & 1,38 \\
Sal comum & 0,35 & 0,35 & 0,35 \\
Suplemento mineral e vitamínico & 0,45 & 0,45 & 0,45 \\
Fitase & 0,00 & 0,04 & 0,04 \\
Xilanase/Inerte & 0,60 & $0,60 *$ & $0,60 *$ \\
TOTAL & $\mathbf{1 0 0}$ & $\mathbf{1 0 0}$ & $\mathbf{1 0 0}$ \\
\hline Composição Nutritiva & & & 2.900 \\
\hline EM (kcal/kg) & 2.900 & 2.900 & 20,68 \\
Proteína bruta (\%) & 20,68 & 20,68 & 0,22 \\
Fósforo disponível (\%) & 0,44 & 0,22 & 0,67 \\
Fósforo total (\%) & 0,67 & 0,56 & 0,75 \\
Cálcio (\%) & 0,93 & 0,75 & 0,44 \\
Metionina (\%) & 0,44 & 0,44 & 1,10 \\
Lisina (\%) & 1,09 & 1,09 & $\mathbf{1 0 0}$ \\
\hline
\end{tabular}

${ }^{1}$ Enriquecimento/kg de ração: Vit. A 8.000 UI, Vit. D 2.000 UI, Vit. E 15 UI, Vit. K 1,8 mg, Vit B1 1,8 mg, Vit. B2 $6 \mathrm{mg}$, Vit. B6 2,8 mg, Vit. B12 $12 \mu \mathrm{g}$, Niacina $40 \mathrm{mg}$, Ác. Fólico $1 \mathrm{mg}$, Ác. Pantotênico $15 \mathrm{mg}$, Biotina $60 \mathrm{mg}$, Selênio 0,3 mg, colina $400 \mathrm{mg}$, Met 1,2 g, Anticoccidiano 0,1 g, promotor de cresc. 0,06 g, Antioxidante 0,03 g, Manganês $75 \mathrm{mg}$, Zinco $50 \mathrm{mg}$, Ferro $50 \mathrm{mg}$, Cobre $8 \mathrm{mg}$ e Iodo 0,75 mg.

* Para cada nível de farelo de arroz, utilizaram-se quatro níveis de xilanase (0, 200, 400 ou $600 \mathrm{~g} /$ tonelada).

${ }^{2}$ FA = Farelo de arroz. 


\section{RESULTADOS E DISCUSSÃO}

Os valores médios de consumo de ração, ganho de peso e conversão alimentar das aves de 1 a 21 dias de idade são apresentados na Tabela 2.

As aves que receberam ração com $20 \%$ de farelo de arroz apresentaram consumo $2,6 \%$ inferior ao daquelas que consumiram ração com $10 \%$ de farelo de arroz, independente do nível de xilanase na ração. Os níveis de xilanase na ração não influenciaram no consumo de ração das aves $(\mathrm{P}>0,05)$.

Ao se comparar as médias de consumo de cada tratamento com a média da testemunha, (sem farelo de arroz e sem enzimas) pelo teste de Dunnett, observa-se que o consumo de ração das aves que receberam ração com $10 \%$ farelo de arroz foi semelhante ao das aves do tratamento-testemunha $(\mathrm{P}>0,05)$, independente do uso ou não de xilanase. Para as rações com $20 \%$ de farelo de arroz, o consumo foi inferior ao consumo das aves do tratamento-testemunha $(\mathrm{P}<0,05)$, exceto para aquelas que receberam ração com $600 \mathrm{~g}$ de xilanase por tonelada, para as quais o consumo foi semelhante ao das aves do tratamento testemunha $(\mathrm{P}>0,05)$.

A inclusão do farelo de arroz em até $10 \%$ na ração não afetou significativamente o consumo de ração das aves, mesmo sem a utilização da xilanase. Por ou- tro lado, a inclusão de $20 \%$ de farelo de arroz causa redução no consumo de ração, o que pode ser revertido pela adição de pelo menos $600 \mathrm{~g}$ de xilanase por tonelada de ração. Farrel e Martim (1998) também verificaram redução de 4 e $20 \%$ no consumo para ração com 20 e $40 \%$ de farelo de arroz, respectivamente. Essa redução no consumo de ração das aves que receberam níveis elevados de farelo de arroz pode ser explicada pela redução da velocidade de passagem da digesta devido à provável elevação de sua viscosidade, a qual pode ser atribuída aos polissacarídeos não-amídicos presentes em teores elevados no farelo de arroz.

A xilanase, em dose adequada, é efetiva em reduzir os efeitos negativos provocados pelos polissacarídeos não-amídicos do farelo de arroz, o que foi observado nas aves que receberam ração com $20 \%$ de farelo de arroz e 600 unidades de xilanase $/ \mathrm{kg}$.

Contrariamente aos resultados deste experimento, Conte (2000), ao estudar o efeito de $1 \mathrm{~kg} /$ tonelada de xilanase (Avizyme 1300) e fitase em rações com $15 \%$ de farelo de arroz para frangos de corte, não encontrou diferença no consumo de ração em função da utilização ou não da xilanase. Esse resultado possivelmente pode estar relacionado com o nível de farelo de arroz estudado pelo autor, que foi inferior ao nível estudado neste experimento, em que foi observada redução no consumo de ração.

TABELA 2 - Consumo de ração,ganho de peso e conversão dos frangos em função dos níveis de xilanase e farelo de arroz na ração de 1 a 21 dias de idade.

\begin{tabular}{|c|c|c|c|c|c|c|}
\hline \multirow{2}{*}{$\begin{array}{c}\text { Xilanase } \\
\text { (g/ton.) }\end{array}$} & \multicolumn{2}{|c|}{ Consumo de Ração (g) } & \multicolumn{2}{|c|}{ Ganho de Peso (g) } & \multicolumn{2}{|c|}{ Conversão Alimentar $(\mathrm{g} / \mathrm{g})$} \\
\hline & $10 \% \mathrm{FA}^{\mathrm{ns}}$ & $20 \%$ FA $^{\text {ns }}$ & $10 \% \mathrm{FA}^{2}$ & $20 \% \mathrm{FA}^{1}$ & $10 \%$ FA $^{\text {ns }}$ & $20 \% \mathrm{FA}^{2}$ \\
\hline 0 & 987 & $984 *$ & $675 *$ & $674 *$ & 1,462 & 1,460 \\
\hline 200 & 1002 & $960 *$ & 709 & $695 *$ & 1,414 & 1,381 \\
\hline 400 & 1008 & $965 *$ & 714 & 709 & 1,411 & $1,360 *$ \\
\hline 600 & 1002 & 988 & 706 & 714 & 1,421 & 1,384 \\
\hline MÉDIA & $1000 \mathrm{a}$ & $974 \mathrm{~b}$ & $701 \mathrm{a}$ & 698 a & $1,427 \mathrm{~b}$ & $1,396 \mathrm{a}$ \\
\hline Testemunha & \multicolumn{2}{|c|}{1051} & \multicolumn{2}{|c|}{734} & \multicolumn{2}{|c|}{1,426} \\
\hline CV (\%) & \multicolumn{2}{|c|}{3,14} & \multicolumn{2}{|c|}{2,31} & \multicolumn{2}{|c|}{2,04} \\
\hline 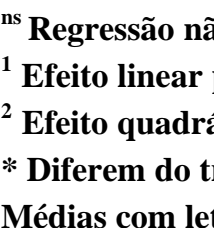 & $\begin{array}{l}\text { gnificativa } \\
\text { a nível de xi } \\
\text { para nível } \\
\text { Imento teste } \\
\text { diferentes }\end{array}$ & $\begin{array}{l}\text { teste } F(P>0 \\
\text { se }(P<0,05) \text {. } \\
\text { ilanase }(P<0 \\
\text { ha pelo test } \\
\text { nha para a } n\end{array}$ & Dunnett ( & 5). & & \\
\hline
\end{tabular}

Ciênc. agrotec., Lavras. V.27, n.6, p.1380-1387, nov./dez., 2003 
Os resultados dos efeitos das enzimas sobre o consumo de ração do presente trabalho confirmam os resultados obtidos por Farrel e Martin (1998),os quais, em estudo para avaliar dois complexos de enzimas contendo xilanase, $\alpha$-amilase, $\beta$-glucanase, protease e fitase para frangos de corte de 1 a 23 dias de idade alimentados com ração à base de sorgo e contendo farelo de arroz variando de zero a $40 \%$ também não verificaram diferença significativa para o consumo de ração entre aquelas aves que receberam a ração sem enzimas, com as enzimas isoladamente ou com as duas enzimas combinadas.

Ganho de peso das aves não foi afetado pelos níveis de farelo de arroz na ração $(\mathrm{P}>0,05)$. Os níveis de xilanase na ração afetaram $(\mathrm{P}<0,01)$ o ganho de peso das aves alimentadas com ração contendo farelo de arroz. O ganho de peso das aves alimentadas com ração contendo $10 \%$ de farelo de arroz apresentou um comportamento quadrático $(\mathrm{Y}=675,9+0,2058 \mathrm{x}-$ $\left.0,0003 \mathrm{x}^{2}-\mathrm{R}^{2}=0,99\right)$, sendo o maior ganho de peso estimado em $716 \mathrm{~g}$ para suplementação com $391 \mathrm{~g}$ de xilanase por tonelada de ração. Já com $20 \%$ de farelo de arroz na ração, o ganho de peso melhorou de forma linear $\left(\mathrm{Y}=677,78+0,0676 \mathrm{x}-\mathrm{R}^{2}=0,93\right)$ em função da elevação do nível de xilanase na ração, significando que o nível ótimo de xilanase para essa variável não foi atingido neste experimento.

Os resultados de ganho de peso encontrados neste experimento diferem daqueles encontrados por Conte (2000), que não verificou efeito da xilanase em ração com $15 \%$ de farelo de arroz para frangos de corte na fase de 1 a 21 dias, embora o autor tenha verificado uma tendência de maior peso para as aves dos tratamentos em que foi utilizada a xilanase, em relação àqueles sem a xilanase. No entanto, deve-se levar em consideração que no trabalho de Conte (2000) foram utilizados níveis de fitase variando de zero a $1200 \mathrm{FTU} / \mathrm{kg}$; portanto, as médias de ganho de peso comparadas com e sem xilanase se referem à média dos tratamentos, ao passo que no presente trabalho, todas as rações com farelo de arroz foram suplementadas com $900 \mathrm{FTU} / \mathrm{kg}$.

Diferentemente dos resultados obtidos no presente trabalho, Aboosadi et al. (1996), em trabalho com frangos de corte alimentados com ração contendo $30 \%$ de farelo de arroz suplementada com 225 unidades xilanase por $\mathrm{kg}$ de ração, e Farrel e Martin (1998), que utilizaram níveis de farelo de arroz variando de zero a $40 \%$, não encontraram diferença significativa para o ganho de peso quando adicionaram enzimas à ração.
Melhora no ganho de peso de 2,2\% também foi relatada em resumo de diversos resultados de trabalhos de pesquisa por Pack e Bedford (1997), em que foi estudado o desempenho de frangos de corte que receberam rações à base de milho e farelo de soja ou sorgo e farelo de soja suplementadas com enzimas semelhantes às utilizadas neste experimento. Garcia (1997) também relatou melhora de 4 e $5 \%$ no ganho de peso de frangos em estudo em que avaliou rações à base de milho e farelo de soja fareladas e peletizadas suplementadas com enzimas similares às utilizadas no presente trabalho.

Pelas comparações das médias de cada tratamento com a testemunha, pelo teste de Dunnett, verifica-se que para o nível de $10 \%$ de farelo de arroz, somente o ganho de peso das aves que consumiram ração sem xilanase foi inferior ao das aves do tratamentotestemunha, inferindo-se que para esse nível de farelo de arroz, a adição de pelo menos $200 \mathrm{~g}$ de xilanase por tonelada de ração já é capaz de eliminar os efeitos negativos dos fatores antinutricionais relacionados aos polissacarídeos não-amídicos, possibilitando ganho de peso estatisticamente semelhante ao das aves que consumiram ração sem farelo de arroz, embora o ganho de peso máximo (716 g) dos frangos que consumiram ração com $10 \%$ de farelo de arroz seja atingido com 391 $\mathrm{g} /$ ton de xilanase na ração.

Para o nível de $20 \%$ de farelo de arroz na ração, o ganho de peso das aves que receberam ração com zero e $200 \mathrm{~g}$ de xilanase foi menor do que o ganho de peso das aves do tratamento-testemunha, quando comparadas pelo teste de Dunnett. Esse resultado significa que a quantidade de xilanase necessária para eliminar os efeitos negativos contidos no farelo de arroz se eleva à medida que aumenta a sua inclusão na ração. Para esse nível de farelo de arroz, $400 \mathrm{~g}$ de xilanase por tonelada de ração foi a quantidade mínima de enzima capaz de propiciar ganho de peso estatisticamente semelhante entre as aves que receberam ração com $20 \%$ de farelo de arroz e aquelas que não consumiram farelo de arroz. Por outro lado, observando-se o efeito linear crescente da elevação do ganho de peso em função do aumento dos níveis de xilanase na ração com $20 \%$ de farelo de arroz, constata-se que a maximização do ganho de peso pode não ter sido atingido, com a maior dose de xilanase utilizada neste experimento. É possível que quantidades superiores a $600 \mathrm{~g}$ de xilanase por tonelada de ração propiciem ganhos de peso ainda melhores.

A conversão alimentar foi afetada $(\mathrm{P}<0,01)$ pelos níveis de farelo de arroz na ração. O nível de $20 \%$ de farelo de arroz na ração propiciou conversão alimen- 
$\operatorname{tar} 2,2 \%$ melhor do que a ração com $10 \%$ de farelo de arroz. Para a ração com $10 \%$ de farelo de arroz, o efeito da elevação dos níveis de xilanase na ração não afetou $(\mathrm{P}>0,05)$ a conversão alimentar dos frangos. $\mathrm{O}$ efeito dos níveis de xilanase dentro do nível de $20 \%$ de farelo de arroz na ração foi quadrático (Y $=1,4596$ $0,00051 x+0,0000006 x^{2}-R^{2}$ ), e pela derivação da equação de regressão, verifica-se que a melhor conversão alimentar para as aves $(1,351)$ pode ser obtida com $425 \mathrm{~g} /$ tonelada de xilanase. Para esse nível, a conversão das aves foi 7,5\% melhor que daquelas aves que consumiram a ração com farelo de arroz sem xilanase, indicando a efetividade da xilanase na melhora da digestibilidade dos nutrientes.

Possivelmente houve melhora na digestibilidade dos nutrientes da ração como um todo, que resulta na melhoria da conversão alimentar, o que pode ser observado pelos resultados deste experimento, que são mais expressivos para o nível mais elevado de farelo de arroz na ração. Como houve uma redução no consumo de ração das aves que receberam ração com $20 \%$ de farelo de arroz e o ganho de peso foi semelhante ao das aves que consumiram a ração contendo $10 \%$ de farelo de arroz, pode-se deduzir que a xilanase foi a responsável pela melhora na conversão alimentar.

Resultados similares ao deste experimento para conversão alimentar de frangos de corte na fase de 1 a 21 dias foram obtidos por Conte (2000), que relatou uma melhora de 5,8\% na conversão alimentar quando adicionou $1,0 \mathrm{~kg}$ de Avizyme 1300 por tonelada de ração com $15 \%$ de farelo de arroz na ração.

Aboosadi et al. (1996), em trabalho com frangos de corte alimentados com ração contendo $30 \%$ de farelo de arroz, não encontraram diferença significativa para a conversão alimentar quando adicionaram 225 unidades de xilanase por $\mathrm{kg}$ de ração, embora tenham verificado uma melhora numérica de $4,4 \%$ na conversão alimentar da ração com xilanase em relação àquela sem xilanase. Possivelmente, a quantidade de enzima não foi suficiente para o nível de farelo de arroz incluído na ração.

Os resultados do presente trabalho discordam dos obtidos por Farrel e Martin (1998), que em estudo para avaliar o efeito de enzimas carboidrases sobre o desempenho de frangos de corte de 4 a 23 dias de idade, alimentados com ração à base de sorgo e contendo zero, 20 ou $30 \%$ de farelo de arroz, verificaram que a conversão alimentar foi significativamente piorada com a elevação dos níveis de farelo de arroz e não verificaram efeito das enzimas. No entanto, neste trabalho não foi utilizada a fitase em quantidades adequadas, além da elevação dos níveis de cálcio na ração, o que deve ter prejudicado o desempenho das aves.

Conte (2000), em estudo do efeito da xilanase sobre a energia metabolizável da ração com $15 \%$ de farelo de arroz, com fitase e xilanase, demonstrou o efeito positivo da xilanase, com uma melhora média de $8 \%$ na energia metabolizável. Giacometti (2002), em estudo dos valores energéticos do farelo de arroz e do efeito de diferentes marcas comerciais de xilanase sobre a energia metabolizável do farelo de arroz para frangos, encontrou melhora de $9,7 \%$ para a conversão alimentar para uma das três enzimas avaliadas em ensaios de metabolismo, em que substituiu $30 \%$ da ração-referência pelo farelo de arroz.

Melhora na conversão alimentar de $2,8 \%$ também foi relatada em resumo de diversos resultados de trabalhos de pesquisa por Pack e Bedford (1997), em que foi estudado o desempenho de frangos de corte que receberam rações à base de milho e farelo de soja ou sorgo e farelo de soja suplementadas com enzimas semelhantes às utilizadas neste experimento.

Para conversão alimentar, não houve diferença em relação à testemunha para as aves que receberam ração contendo $10 \%$ de farelo de arroz. Para as aves que receberam ração contendo $20 \%$ de farelo de arroz, foi verificado, pela comparação pelo teste de Dunnett, que os frangos que consumiram ração com 400 gramas de xilanase apresentaram conversão alimentar significativamente melhor que as aves que receberam a ração sem farelo de arroz e sem enzimas.

\section{CONCLUSÕES}

A suplementação de xilanase foi efetiva para melhorar o desempenho e seus efeitos foram mais pronunciados na ração com níveis mais elevados de farelo de arroz.

A elevação dos níveis de inclusão de farelo de arroz na ração sem xilanase prejudica o desempenho produtivo.

O nível máximo de farelo arroz na ração não deve ultrapassar $10 \%$ na ração sem suplementação com xilanase.

É viável a formulação de rações para frangos com até $20 \%$ de farelo de arroz, com a utilização de $400 \mathrm{~g}$ da enzima xilanase por tonelada.

Em relação ao desempenho produtivo na fase de 1 a 21 dias de idade, a utilização de farelo de arroz em ração para frangos de corte, sem comprometer nenhu- 
ma das variáveis de desempenho, é possível com a suplementação de pelo menos $350 \mathrm{~g} /$ ton para ração com $10 \%$ de farelo de arroz e de $600 \mathrm{~g} / \mathrm{ton}$, quando a ração contém $20 \%$ de farelo de arroz na fase de 1 a 21 dias de idade.

\section{REFERÊNCIAS BIBLIOGRÁFICAS}

ABOOSADI, M. A.; SACIFE, J. R.; MURRAY, I.; BEDFORD, M. Effect of supplementation cell wall degradation enzymes on the growth the performance of broiler chickens fed diets containing rice bran. British Poultry science, Edinburgh, v. 37, n. S42, Sept. 1996. Abstract.

AGRIANUAL'01: anuário da agricultura brasileira. São Paulo: FNP/Argos, 2001.

AGROCERES ROSS. Manual de manejo de frangos de corte Ross. São Paulo, 2001.

ALI, M. M.; HUSSAIN, M. G.; NURUL, A. B. S. A. R.; SHAHJAHAN. M.; ABSAR, N. Investigation on rice bran: composition of rice bran and its oil. Bangladesh Journal of Scientific and Industrial Research, Dhaka, v. 33, n. 2, p. 170-177, 1998.

ASSOCIATION OF OFFICIAL ANALYTICAL CHEMIST. Official methods of analysis: agricultural chemicals, contaminants and drugs. 15. ed. Washington, 1990. v. 1, 684 p.

CONTE, A. J. Valor nutritivo do farelo de arroz em dietas para frangos de corte, com utilização das enzimas fitase e xilanase. 2000. 151 p. Tese (Doutorado) - Universidade Federal de Lavras, Lavras, 2000.

DOMENE, S. M. A. Estudo do valor nutritivo mineral do farelo de arroz: utilização do zinco, ferro, cobre e cálcio pelo rato em crescimento. 1996. 104 f. Tese (Doutorado em Ciência da Nutrição) - Universidade Estadual de Campinas, Campinas, 1996.

FARREL, D. J.; MARTIN, E. A. Strategies to improve the nutritive value of rice bran in poultry diets. I: the addition of food enzymes to target the non-starch polysaccharide fractions in diets of chickens and ducts gave no response. British Poultry Science, Cambridge, v. 39, n. 4, p. 549-554, Sept. 1998.

GARCIA, O. Enzimas: recentes contribuições para a sua aplicação em nutrição animal. In: ENCONTRO DE NUTRIÇÃO ANIMAL, 3., 1997, São Paulo. Anais... São Paulo: [s.n.], 1997. p. 1-9.

GIACOMETTI, R. A. Valores energéticos e digestibilidade de nutrientes do farelo de arroz integral suplementado com complexos enzimáticos para frangos de corte. 2002. 54 p. Dissertação (Mestrado em zootecnia) - Universidade Federal de Lavras, Lavras, 2002.

PACK, M.; BEDFORD, M. Feed enzymes for cornsoybean broiler diets: a new concept to improve nutritional value and economics. World's Poultrtry Science Journal, London, v. 53, n. 1, p. 87-93, Mar. 1997.

RAVINDRAN, V.; BLAIR, R. Feed resources for poultry production in asia and the Pacific region. I: energy sources. World's Poultry Science Journal, London, v. 47, n. 4 p. 211-231, Nov. 1991.

ROSTAGNO, H. S.; ALBINO, L. F. T.; DONZELE, J. L.; GOMES, P. C.; FERREIRA, A. S.; OLIVEIRA, R. F.; LOPES, D. C. Tabela brasileira para aves e suínos: composição de alimentos e exigências nutricionais. 2. ed. Viçosa: UFV, 2000. 141 p.

SHIBUTA, N.; NAKANE, R.; YASUI, A.; TANAKA, K.; IWASAKI, T. Comparative studies on cell wall preparations fron rice bran, germ, and endosperm. Cereal Chemistry, Saint Paul, v. 62, n. 4, p. 252-258, July/Aug. 1985.

UNIVERSIDADE ESTADUAL PAULISTA. Estat 2.0: sistema de análise estatística. Jaboticabal: UNESPDepartamento de Ciências Exatas-Pólo Computacional, 1992. 